\title{
Transcriptional analysis of CXCR4, DNMT3A, DNMT3B and DNMT1 gene expression in primary advanced uterine cervical carcinoma
}

\author{
MICHAŁ W. ŁUCZAK ${ }^{2 *}$, ANDRZEJ ROSZAK $^{1 *}$, PIOTR PAWLIK $^{3,4}$, HELENA KĘDZIA $^{4}$, WITOLD KĘDZIA $^{5}$, \\ BLANKA MALKOWSKA-WALCZAK ${ }^{5}$, MARGARITA LIANERI ${ }^{2}$ and PAWEŁ P. JAGODZIŃSKI ${ }^{2}$ \\ ${ }^{1}$ Department of Radiotherapy and Gynecological Oncology, Greater Poland Cancer Centre Poznań; \\ Departments of ${ }^{2}$ Biochemistry and Molecular Biology, ${ }^{3}$ Surgical Gynecology, ${ }^{4}$ Pathology and \\ ${ }^{5}$ Obstetrics and Gynecology, Poznań University of Medical Sciences, Poznań, Poland
}

Received June 22, 2011; Accepted August 10, 2011

DOI: $10.3892 /$ ijo.2011.1183

\begin{abstract}
The development of cervical cancer requires genetic and epigenetic factors which result in the persistence of a malignant phenotype. Cervical cancer exhibits also some unique differences from other solid tumors. Normal cervical stratified epithelia have characteristics of hypoxic tissue with over-expression of HIF-1 (hypoxia-inducible factor-1) transcription factor, which targets the transcription of over 70 genes involved in many aspects of cancer biology. One of the genes, which could be induced by HIF-1 is chemokine (C-X-C motif) receptor 4 (CXCR4). CXCR4 could also be epigenetically regulated by methylation of $\mathrm{CpG}$ dinucleotides located in the promoter region. Here, we examined the CXCR4, DNMT3A, DNMT3B and DNMT1 transcript levels in cancer tissue $(n=30)$ and non-cancer, normal uterine cervical tissue $(n=30)$ from a Polish cohort. We also compared the methylation status of CXCR4 promoter region in cancer and normal tissue samples. Our result showed significantly higher levels of CXCR4, DNMT3A, DNMT3B and DNMT1 transcript $(\mathrm{p}=0.0058,0.0163,0.0003$ and $<0.0001$, respectively) levels in cancer tissue as compared to normal samples. We did not observe DNA methylation in the CXCR4 promoter region in either control or cancer tissue samples. CXCR4 has a functional hypoxia response element (HRE) in the promoter region, located $-1.3 \mathrm{~kb}$ from the transcription start site. Our work shows for the first time that HIF-1A could promote the induction of CXCR4 gene expression (Spearman's correlation coefficient $=0.515, \mathrm{p}=0.003$ ) in patients with primary advanced uterine cervical carcinoma.
\end{abstract}

Correspondence to: Dr Michał W. Łuczak, Department of Biochemistry and Molecular Biology, Poznań University of Medical Sciences, 6 Święcickiego St., 60-781 Poznań, Poland

E-mail:mluc@ump.edu.pl

*Contributed equally

Key words: cervical cancer, hypoxia, HIF-1A, CXCR4, DNMTs

\section{Introduction}

Worldwide, cervical cancer is the second most common cancer in women (after breast cancer), with more than half a million new cases diagnosed in 2005 (1). The primary etiological factor associated with cervical cancer development is exposure to the human papillomavirus (HPV), particularly types 16 and 18 (2). The development of cervical cancer requires additional genetic and epigenetic factors which result in the persistence of a malignant phenotype (3). One of these genetic factors are mutations in the germ line or changes in DNA sequences arising in somatic tissues during life (4). These mutations may abnormally enhance the function of proto-oncogenes, or erase effects of the tumor suppressor gene products $(5,6)$. One of the most important epigenetic factors associated with cancer development is DNA methylation. DNA methylation occurs primarily in $\mathrm{CpG}$ dinucleotides, called 'CpG islands', located in 5' upstream sequences of gene promoters. The methylation of mammalian genomic DNA appears to be established by a complex interplay of at least three independently encoded DNA methyltransferases (DNMTs), including de novo (DNMT3A and DNMT3B) and maintenance (DNMT1) enzymes (7-9). Most promoter regions in animal genomes are methylated, while $\mathrm{CpG}$ islands located in housekeeping genes are constitutively demethylated (10). Global genome demethylation (hypomethylation) is usually associated with cellular differentiation during early development $(11,12)$. Furthermore, malignant cells also exhibit hypomethylation of various DNA regions (13), which activates the transcription of proto-oncogenes, retrotransposons, and genes encoding proteins associated with genomic instability, invasion and metastasis (4). Moreover, hypermethylation of various tumor suppressor genes causes their transcriptional silencing and removes a barrier of normal proliferation, which may result in malignant transformation. Most interestingly, overexpression of DNMT1 and DNMT3B has been found to be common in human tumors (14-17), and this overexpression could also be associated with HPV infections (18-20).

Under low $\mathrm{O}_{2}$ (hypoxic) conditions, cells activate a number of adaptive responses to match $\mathrm{O}_{2}$ supply with metabolic, bioenergetic, and redox demands. Hypoxia induces hypoxia- 
inducible factor-1 (HIF-1), which has been identified as an important transcription factor that mediates the cellular response to hypoxia. HIF-1 is a heterodimer composed of one of three $\alpha$ subunits (HIF- $1 \alpha, \mathrm{HIF}-2 \alpha$ or HIF- $3 \alpha$ ) and one HIF- $1 \beta$ subunit. HIF- $1 \beta$ is constitutively expressed and identical to the aryl hydrocarbon receptor, known as AhR nuclear translocator (ARNT) (21). In well-oxygenated environments, HIF-1 $\alpha$ subunits are hydroxylated at conserved proline $\mathrm{Pro}^{402}$ and $\mathrm{Pro}^{564}$ residues. These modifications are mediated by proline hydroxylases (PHDs), whose activity is regulated by $\mathrm{O}_{2}$ availability (22). Hydroxylated HIF-1 $\alpha$ forms hydrogen bonds with pVHL (von Hippel Lindau protein) side chains, which promote polyubiquitination of HIF-1 $\alpha$, followed by 26S-proteasomal degradation (23). Under hypoxic stress, PHD activity is diminished. Stabilized HIF- $1 \alpha$ is involved in the activation of numerous cellular processes $(24,25)$, and this stabilization of HIF-1 $\alpha$ is observed in a vast number of solid tumors (26). Adaptation to hypoxic stress via HIF-1 transcriptional factor is highly complex and depends on the presence of hypoxia response element (HRE) in the promoter region of genes supporting anaerobic metabolism. One of the genes with a functional HRE in its promoter region is chemokine (C-X-C motif) receptor 4 (CXCR4). The presence of HRE suggests that this gene could be regulated by hypoxia via HIF-1 transcriptional factor.

Here, we studied the transcript levels of the CXCR4, DNMT3A, DNMT3B and DNMT1 genes in cancer and noncancer (control) uterine cervical tissue from a Polish cohort. We also analyzed CXCR4 promoter methylation in cancer and control tissue samples.

\section{Materials and methods}

Tissue samples. Cancer and non-cancer (control) tissue samples were collected from Caucasian women of the Wielkopolska district of Poland and represent the female Polish population. Samples were collected from patients undergoing gynecological procedures at the Department of Radiotherapy, Greater Poland Cancer Center in Poznań, Poland. Normal uterine cervical samples were obtained from women undergoing uterine surgical resection in Department of Surgical Gynecology, Poznań University of Medical Sciences, Poland. Cancer $(n=30)$ and control specimens $(n=30)$ were collected following approval by the Local Ethics Committee of Poznań University of Medical Sciences. Written informed consent was obtained from all participating patients.

All speciments were subjected to initial H\&E staining (27), followed by review by an experienced pathologist. Cervical sections with cancer cells were used as cancer samples. The same criteria were applied to identify non-cancer, normal cervical tissue samples. After surgical removal, tissue samples were frozen in liquid nitrogen and stored at $-80^{\circ} \mathrm{C}$ until used. All 30 studied patients had squamous cell carcinoma (SCC). Among 30 patients with SCC, 1 patient was classified as stage II, 28 as stage III and 1 as stage IV, based on the International Federation of Gynecology and Obstetrics (FIGO) classification system (Table I).

Reverse-transcription and real-time quantitative $P C R(R Q-P C R)$ analysis of CXCR4, DNMT3A, DNMT3B and DNMT1 transcripts. Total RNA from control and cancer tissue samples was
Table I. Clinical characteristics of patients with cervical cancer and healthy controls.

\begin{tabular}{lcc}
\hline Characteristics & $\begin{array}{c}\text { Patients } \\
\mathrm{n}=30\end{array}$ & $\begin{array}{c}\text { Controls } \\
\mathrm{n}=30\end{array}$ \\
\hline Mean age (years) $\pm \mathrm{SD}$ & $52.6 \pm 11.7$ & $48.2 \pm 6.8$ \\
Tumor stage & & \\
II & $1 \quad(3.3 \%)$ & \\
III & $28(93.4 \%)$ & \\
IV & $1 \quad(3.3 \%)$ & \\
Histological grade & & \\
G1 & $1 \quad(3.3 \%)$ & \\
G2 & $18(60.0 \%)$ & \\
G3 & $11(36.7 \%)$ & \\
\hline
\end{tabular}

isolated using TRI Reagent (Sigma-Aldrich Chemie Gmbh, Steinheim, Germany) according to the method of Chomczynski and Sacchi (28). RNA integrity was confirmed by denaturing agarose gel electrophoresis, and the concentration was quantified by measuring the optical density (OD) at $260 \mathrm{~nm}$ using BioPhotometer (Eppendorf AG, Hamburg, Germany). RNA samples were treated with DNase I and reverse-transcribed into cDNA using oligo-dT primers. Reverse transcription was performed using M-MLV Reverse Transcriptase (Invitrogen, Carlsbad, CA) as described in the manufacturer's protocol.

The quantitative real-time RT-PCR assay was performed using the CFX96 real-time PCR detection system (Bio-Rad Laboratories, CA, USA) using iQ Sybr Green as detection dye. Target cDNA was quantified by relative quantification method using a calibrator. For the calibrator, $1 \mu \mathrm{l}$ of cDNA from all samples were mixed together. To create a standard curve, five 2-fold serial dilutions of the cDNA were used. The cycle threshold was recorded and plotted as a function of the dilution to generate a straight line with a slope that was related to the doubling efficiency $\left(10^{-1 / \text { slope }}\right)$. The efficiency raised to the value of the intercept of the line at no dilution is a measure of the relative amount of cDNA for each gene in the tissue samples. The quantity of CXCR4, DNMT3A, DNMT3B and DNMT1 transcripts in each sample was standardized by PBGD transcript level. For amplification, $5 \mu \mathrm{l}$ of iQ Sybr Green Supermix (Bio-Rad Laboratories), $1 \mu$ l of primers (Oligo, Warsaw, Poland) (Table II), $3 \mu \mathrm{l}$ of water (Sigma-Aldrich Chemie) and $1 \mu \mathrm{l}$ of cDNA solution were mixed together. One RNA sample of each preparation was processed without RT-reaction to provide a negative control in subsequent PCR. Sample amplification included a hot start $\left(95^{\circ} \mathrm{C}, 3 \mathrm{~min}\right.$ ) followed by 50 cycles of denaturation at $95^{\circ} \mathrm{C}$ for $10 \mathrm{sec}$, annealing at $60^{\circ} \mathrm{C}$ for $10 \mathrm{sec}$, and extension at $72^{\circ} \mathrm{C}$ for $8 \mathrm{sec}$. After amplification Melt Curve analysis was performed to analyze product melting temperature. The amplification products were resolved by $3 \%$ agarose gel electrophoresis and visualized by ethidium bromide staining. One sample of each primer pair was also used for commercial sequencing analysis.

Sodium bisulfite DNA sequencing of CXCR4 promoter region. Genomic DNA from control and cancer tissues was extracted 
Table II. Primer pairs used for DNA amplification of studied gene fragments.

\begin{tabular}{llccc}
\hline Gene & \multicolumn{1}{c}{ Sequence (5'-3' direction) } & Position & ENST no. & Product size (bp) \\
\hline CXCR4 & AAGATTGGTAGGTGTAAGTG & $-1198--1179$ & 00000241393 & 401 \\
& TTTCATTTCCTCACTCTCCC & $-817--798$ & & 130 \\
CXCR4 & TTCTTAACTGGCATTGTGGG & $+157--176$ & 00000241393 & \\
& GAAGCGTGATGACAAAGAGG & $+267-+286$ & & 178 \\
DNMT3A & GGTGCTGTCTCTCTTTGATG & $+2243-+2262$ & 00000264709 & 183 \\
& ATGCTTCTGTGTGACGCTG & $+2402-+2420$ & & 149 \\
DNMT3B & GGAAGGAGTTTGGAATAGGG & $+980-+999$ & 00000328111 & \\
& CCAGTGCCACCAGTTTGTC & $+1144-+1162$ & & 160 \\
DNMT1 & GATGAGAAGAAGCACAGAAGT & $+1128-+1148$ & 00000359526 & \\
& TCTTTGGGGGTCGTTTTGC & $+1257-+1276$ & & \\
PBGD & GCCAAGGACCAGGACATC & $+833-+850$ & 00000278715 & \\
& TCAGGTACAGTTGCCCATC & $+974-+992$ & & \\
\hline
\end{tabular}

using the salting-out method. Extracted DNA was treated using EZ DNA Methylation Kit ${ }^{\mathrm{TM}}$ (Zymo Research Corp., Orange, CA), according to the manufacturer's protocol. The location of $\mathrm{CpG}$ islands in the promoter regions of the CXCR4 gene was determined by a program found at http://www.ebi.ac.uk/ emboss/cpgplot/ (Fig. 2). The promoter regions containing $\mathrm{CpG}$ islands were amplified by the primer pairs (Table II) complementary to the modified DNA. For amplification, $1.5 \mu 1$ of 10X concentrated PCR buffer (Roche, Mannheim, Germany), $2.4 \mu \mathrm{l}$ of $25 \mathrm{mM} \mathrm{MgCl}_{2}$ (Roche), $1.2 \mu \mathrm{l}$ of $2.5 \mathrm{mM}$ dNTPs (Novazym, Poznan, Poland), $0.6 \mu \mathrm{l}$ of each $10.0 \mu \mathrm{M}$ primers (Oligo), $0.2 \mu \mathrm{l}$ of FastStart Taq DNA Polymerase $(5 \mathrm{U} / \mu \mathrm{l})$ (Roche, Mannheim, Germany), $6.5 \mu 1$ of water (Sigma-Aldrich Chemie) and $2 \mu \mathrm{l}$ of modified DNA were used. One PCR reaction of each preparation was processed without a DNA template to provide a negative control in subsequent PCR. Sample amplification included a hot start $\left(95^{\circ} \mathrm{C}, 5 \mathrm{~min}\right)$ followed by 49 cycles of denaturation at $95^{\circ} \mathrm{C}$ for $35 \mathrm{sec}$, annealing at $56^{\circ} \mathrm{C}$ for $35 \mathrm{sec}$, extension at $72^{\circ} \mathrm{C}$ for $45 \mathrm{sec}$ and final extension at $72^{\circ} \mathrm{C}$ for $7 \mathrm{~min}$. The amplifcation products were resolved by $1.5 \%$ agarose gel electrophoresis and visualized by ethidium bromide staining. The PCR products were purified using Agarose Gel DNA Extraction Kit Roche (Mannheim, Germany) and cloned into pGEM-T Easy Vector System I Promega (Madison, WI) following transformation into TOPO10 E. coli strain cells. Plasmid DNA extracted with Pure Yield Plasmid Miniprep System (Promega, Madisaon, WI) from ten positive bacterial clones was used for commercial sequencing of the cloned fragments of DNA.

Statistical analysis. Data groups for cell lines were assessed by ANOVA to evaluate if there was significance $(\mathrm{p}<0.05)$ between the groups. For all experimental groups, which fulfilled the initial criterion, individual comparisons were performed by post hoc Tukey test with the assumption of two-tailed distribution and two samples with equal variance at the $\mathrm{P}<0.05$ level. The normality of the observed patient data distribution was assessed by Shapiro-Wilk test and unpaired, two-tailed t-test or Mann-Whitney test was used to compare the mean values. $\mathrm{P}<0.05$ was considered statistically significant. Spearman's rank correlation was used to determine whether a correlation between the analyzed gene expression was positive or negative. Positive correlation is taken to mean that the expression of one gene increases when the expression of the gene it is being compared to also increases. Negative correlation is taken to mean that the expression of a gene decreases when the expression of the gene it is being compared to increases.

\section{Results}

Increased CXCR4 expression in primary advanced uterine cervical carcinoma may be induced by hypoxia and CXCR4 overexpression is not associated with epigenetic regulation due to overexpression of DNMTs. RQ-PCR was used to compare CXCR4, DNMT3A, DNMT3B and DNMT1 transcript levels in control and cancer tissues. Our results show significantly higher levels of CXCR4, DNMT3A, DNMT3B and DNMT1 transcript ( $p=0.0058,0.0163,0.0003$ and $<0.0001$, respectively) levels in cancer tissue samples compared to the control tissue samples (Fig. 1 and Table III). We did not find significant differences between transcript levels in comparing patient groups with different tumor stage and histological grade. We also did not observe changes in the DNA methylation pattern in the CXCR4 promoter region in either control or cancer tissue samples (data not shown). In our previous report we found significantly increased HIF-1A transcript and protein levels in tumor tissue samples compared to their normal, non-cancer counterpart (29). A statistically significant association was found between HIF-1A 
A
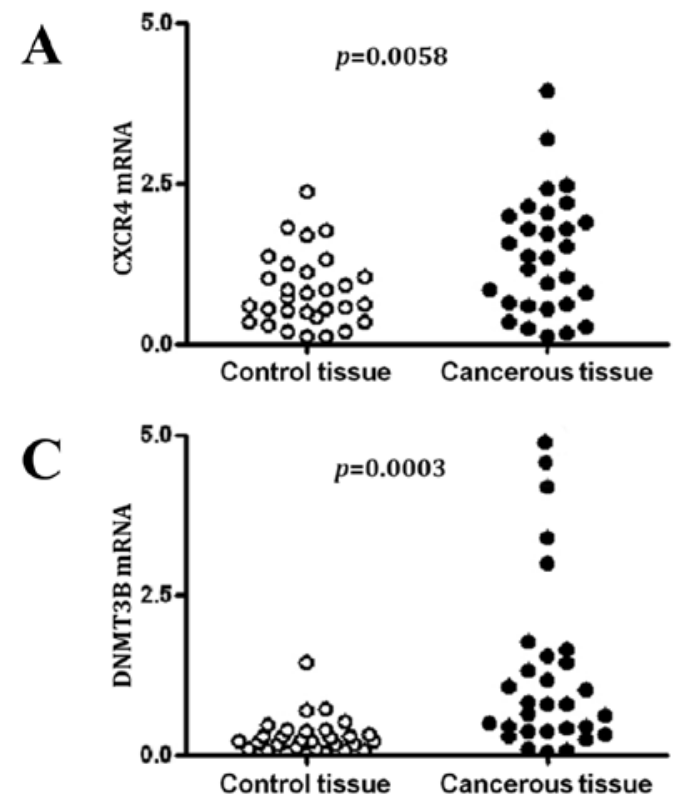

B

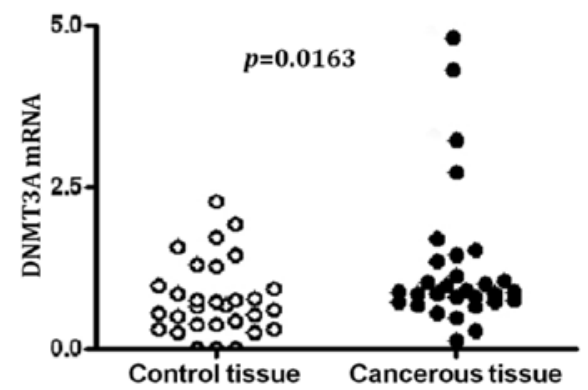

D

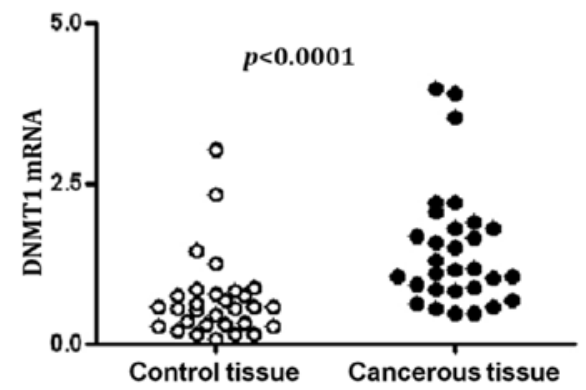

Figure 1. CXCR4 (A), DNMT3A (D), DNMT3B (C) and DNMT1 (D) transcript levels in non-cancer, control tissues and in advanced uterine cervical carcinoma.

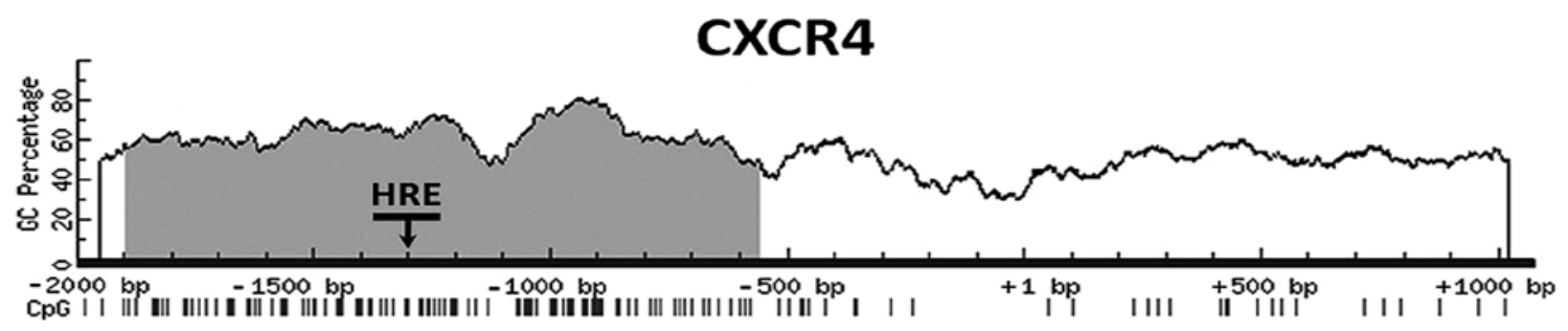

Figure 2. The structure of the CXCR4 promoter. The HRE located $-1.3 \mathrm{~kb}$ in the CXCR4 promoter is critical for the hypoxia HIF-1 inducible activity of the CXCR4 gene. This HRE is located in the region of $\mathrm{CpG}$ islands of the CXCR4 gene (dark color).

and CXCR4 expression (Spearman's correlation coefficient $=$ $0.445, \mathrm{p}=0.01)$.

\section{Discussion}

Cervical cancer is a gynecological malignancy with one of the highest mortality rates of women worldwide. Cervical cancer exhibits some unique characteristics that are different from other solid tumors. Healthy cervical cells have characteristics of chronically hypoxic tissue $(30,31)$ with partial stabilization of the HIF-1 $\alpha$ protein. This stabilization increases during carcinogenesis and the progression of cervical cancer. Increased vascularity, as a result of stabilized HIF- $1 \alpha$ protein, is observed in low grade cervical cancer, while such stabilization is a late event in the progression of many other solid cancers $(31,32)$. In non-cancer, well-oxygenated tissue (normoxia), HIF-1 $\alpha$ subunits are continuously hydroxylated at conserved proline residues, located in the oxygen-dependent degradation domain, by proline hydroxylases (PHDs), whose activities are $\mathrm{O}_{2}$ dependent (22). The inhibition of PHDs activity is critical for HIF-1 $\alpha$ stabilization and escape from proteosome degradation during hypoxia (33-35). In addition to hypoxia, other factors independent of hypoxia can promote HIF-1 $\alpha$ protein stabilization and accumulation via translational or post-translational mechanisms (36). HIF-1A as a transcription factor can target the transcription of over 70 genes (36) involved in the cellular response to hypoxia $(25,26)$, such as induction of proliferation, migration, and blood vessel formation by endothelial cells (37). Transcription of hypoxia-inducible genes is regulated by one or more hypoxia response elements (HREs) located in either the promoter or enhancer regions (38). The majority of hypoxia induced gene HRE contains a HIF-1 ancillary sequence (HAS), which is located 8-9 nt down- or upstream of hypoxia binding sites. This sequence is necessary for HIF-1A mediated transcription activation (38). Furthermore, efficient gene activation requires recruiting of additional transcriptional factors, such as ATF-1/CREB-1, AP-1 and HNF-4 factor (39), which are not hypoxia dependent. Single nucleotide mutations or epigenetic alternation may remove binding sites for transcription factors, which are required for hypoxia HIF-1 induced gene expression (39). Nucleotides located close to HRE in the promoter sequence can also affect HIF-1 gene activation (36). Therefore, mutations or $\mathrm{CpG}$ methylation present in the promoter region of a gene could perturb the gene activation via HIF-1.

The CXCR4 receptor binds the chemokine CXCL12 and activates intracellular signaling pathways that promote survival, proliferation and migration of cancer cells (40). CXCR4 is expressed in a wide variety of non-cancer tissues such as bone marrow, blood, spleen, thymus, lymph nodes, and the pituitary 
Table III. CXCR4, DNMT3A, DNMT3B and DNMT1 transcript levels in advanced uterine cervical carcinoma and corresponding control tissues.

\begin{tabular}{lllllll}
\hline & \multicolumn{2}{c}{ Control tissue } & & \multicolumn{2}{c}{ Cancer tissue } & \\
\cline { 2 - 3 } & Median (range) & Mean $( \pm \mathrm{SD})$ & & Median (range) & Mean $( \pm \mathrm{SD})$ & $\mathrm{p}$-value \\
\hline CXCR4 & $0.68(0.13-2.35)$ & $0.82 \pm 0.56$ & & $1.35(0.11-3.95)$ & $1.39 \pm 0.93$ & $0.0058^{\mathrm{a}}$ \\
DNMT3A & $0.65(0.01-2.26)$ & $0.76 \pm 0.57$ & & $0.87(0.26-4.81)$ & $1.26 \pm 1.10$ & $0.0163^{\mathrm{b}}$ \\
DNMT3B & $0.22(0.07-1.45)$ & $0.29 \pm 0.28$ & & $0.80(0.07-5.07)$ & $1.28 \pm 1.38$ & $0.0003^{\mathrm{a}}$ \\
DNMT1 & $0.56(0.13-2.32)$ & $0.68 \pm 0.63$ & & $1.16(0.46-3.97)$ & $1.48 \pm 0.94$ & $0.0001^{\mathrm{b}}$ \\
\hline
\end{tabular}

The target mRNA levels were corrected to the amount of PBGD cDNA and expressed as multiplicity of these cDNA copies in the calibrator. ${ }^{a}$ Unpaired, two-tailed t-test. ${ }^{\mathrm{b}}$ Mann-Whitney test.

and adrenal glands (40), as well as in ovarian, breast, lung, prostate, stomach, colon, kidney, brain, thyroid, liver, pancreatic, esophageal, cervical, and oral cancers, and melanoma and leukemia (40). Expression of CXCR4 could also be epigenetically regulated by methylation of $\mathrm{CpG}$ dinucleotides located in the promoter region. Computational analysis demonstrated that $\mathrm{CpG}$ islands are located in the promoter region of the CXCR4 gene (Fig. 2). Therefore, we also analyzed the expression levels of those DNMTs that could regulate the expression of the CXCR4 gene epigenetically.

The expression of CXCR4 has been investigated in different tumor types. Chick and Szyf (41) and Ateeq et al (42) demonstrated that the demethylating agent 5'-aza-2'-deoxycytidine induced prometastatic CXCR4 gene expression by the demethylation of its promoter in MCF-7 and ZR-75-1 breast cancer cell lines. By contrast, the results presented by Dejeux et al (43) in a group of 6 normal breast tissue samples and 163 unselected samples from locally advanced breast cancer did not demonstrate methylation of $\mathrm{CpG}$ located in the promoter region of the CXCR4 gene either the non-cancer samples nor in the breast cancer samples. Przybylski et al (44) and Sato et al (45) analyzed the methylation status of the CXCR4 gene in pancreatic cell lines. Przybylski et al (44) employed knockdown of the DNMT1 and DNMT3B genes in AsPC1 pancreatic cancer cell line and demonstrated that depletion of both of these genes was associated with CXCR4 promoter demethylation and the production of CXCR4 transcript and protein. Sato et al (45) demonstrated that $\mathrm{CpG}$ islands of the CXCR4 gene were unmethylated in normal pancreatic ductal epithelial samples, whereas promoter hypermethylation was detected in pancreatic cancer cell lines and in primary pancreatic adenocarcinomas (45). Promoter methylation of the CXCR4 gene was also reported in estrogen receptor positive Ishikawa endometrial adenocarcinoma (46), melanoma cells (47) and in patients with primary myelofibrosis (48). The levels of CXCR4 have also been evaluated in cervical cancer but using only an immunohistochemical method. Kodama et al (49) examined the immunostaining profiles of CXCR4 in 174 cervical cancer patients presenting with stage IB-IIB cervical cancers. The authors concluded that the expression of CXCR4 may be associated with lymph node metastasis and also provide evidence that CXCR4 expression can serve as an indicator of poor prognosis in patients with cervical cancer. Similar results were presented by Zhang et al (50). Immunohistochemical detection of CXCR4 in 35 analyzed squamous cell carcinoma tissue samples revealed that this gene probably participates in lymph node metastasis in cervical cancer (50).

Also, Yang et al (51) demonstrated that immunohistochemically detected CXCR4 expression was associated with cervical adenocarcinoma cell migration and proliferation. Moreover, cancer cells expressing CXCR4 were significantly more likely to metastasize to pelvic lymph nodes (51). Interestingly, Rein et al (52) used purified primary cervical cancer cells from three patients, normal control cervical cells from healthy women, as well as various established cervical cancer cell lines, and demonstrated that the CXCR4 promoter was active only in the cancer cervical tissues and cancer cell lines but its activity was low.

Staller et al (40) showed that the HRE located $-1.3 \mathrm{~kb}$ in the CXCR4 promoter is critical for the hypoxia HIF-1 inducible activity of this gene, and this HRE is located in the region of $\mathrm{CpG}$ islands of the CXCR4 gene (Fig. 2). Tang et al (53) were the first to report the expression of HIF-1A target CXCR4 gene expression in HIF-1A-transfected SiHa cells. Overexpression of HIF-1A affects the proliferation, apoptosis, and migration of SiHa cells in part by regulating the expression of its target gene, CXCR4.

Our experiments clearly show that the CXCR4 gene is not epigenetically regulated in primary advanced cervical carcinoma. We did not observe methylation in the promoter region of the CXCR4 gene in either the control tissue samples or the cancer tissue samples (data not shown). Moreover, we observed an overexpression of the CXCR4 gene in tumor tissue samples compared to their normal, non-cancer counterparts, which could be associated with increased levels of HIF-1A (29); we found a statistically significant, positive Spearman's rank correlation, between HIF-1A and CXCR4 expression. Thus, our results show for the first time that HIF-1A could promote the induction of CXCR4 gene expression in patients with primary advanced uterine cervical carcinoma. Our results are the first to confirm, on a patient level, the results presented by Tang et al (53).

DNMT3A is thought to function in de novo methylation and its expression is developmentally regulated by its different isoforms (54-56). DNMT3A -/- knock-out mice appear to be normally developed, but die shortly after birth (57). However, the relationship between DNMT3A and tumorigenesis is still largely unknown. Deng et al (58) reported that 
inhibition of DNMT3A expression, by stable transfection of a DNMT3A-RNA interference construct, dramatically inhibited melanoma growth and metastasis in mouse melanoma models. $\mathrm{Ng}$ et al (59) described an upregulation of DNMT3A in primary colorectal cancer tissues compared with their paired non-cancer colonic tissues. Also, Daniel et al (60), using an immunohistochemical method, reported overexpression of DNMT3A in oral squamous cell carcinoma (grade I-III) specimens compared to control tissues. Similar results were presented by Qu et al (61) in patients with retinoblastoma. Zhao et al (62) were the first who provided evidence that DNMT3A could be involved in promoter hypermethylation during carcinogenesis. The authors observed increased DNMT3A expression in hepatocellular carcinoma cell lines and tissue samples. Knockdown of DNMT3A in the SMMC-7721 cell line revealed that 153 genes were upregulated and 91 of them contained $\mathrm{CpG}$ islands in their 5' promoter region. Moreover, 13 of them were crucial tumor suppressor genes involved in the cell cycle and cell proliferation (62). The most recent data on preferential target sites for human DNA methyltransferases, including distinct isoforms of DNMT3A, is reported by Choi et al (63).

DNMT1 (64) and DNMT3B (65) were both shown to be important for cancer cell survival and tumorigenesis, and the overexpression of these genes has been described in many different tumor types (17). Only Sawada et al (66) analyzed the protein levels of DNMT1 in histologically normal squamous epithelium, low-grade (CIN1) and higher-grade (CIN2 and CIN3) cervical intraepithelial neoplasia, and samples of squamous cell carcinoma of the uterine cervix using an immunohistochemical examination. These authors observed progressively increased levels of DNMT1 protein with increasing cancer grades and a plateau in microinvasive carcinoma. These data suggest that expression of the DNMT1 protein is associated with an early step of multistage cervical carcinogenesis. DNMT1 protein overexpression is a very early event during multistage cervical carcinogenesis because DNMT1 may be activated by the HPV-16 E7 protein (66). The HPV-16 E7 protein has been reported to directly associate with DNMT1 and stimulate the methyltransferase activity of DNMT1 in vitro (67). Au Yeung et al (18) reported that HPV-16 E6 could also up-regulate DNMT1 expression in human cervical cancer cell lines. Our research is the first to show a complete transcriptional analysis of the DNMT1, DNMT3B and DNMT3A methyltransferases in primary advanced uterine cervical carcinoma. The expression of all of the analyzed DNMTs was significantly increased in primary advanced cervical carcinoma compared to non-cancer counterparts.

In conclusion, we are the first to demonstrate increased CXCR4, DNMT3A, DNMT3B and DNMT1 transcript levels in advanced uterine cervical carcinoma. We also observe that the increase in CXCR4 expression could be HIF-1A dependent and the CXCR4 gene is not epigenetically regulated by overexpressed methyltransferases.

\section{Acknowledgements}

This study was supported by grants No. N N407 090236 and N N407 049538 from Polish Ministry of Scientific Research and Information Technology.

\section{References}

1. Liyanage SH, Roberts CA and Rockall AG: MRI and PET scans for primary staging and detection of cervical cancer recurrence. Womens Health 6: 251-267, 2010.

2. Smith JS, Lindsay L, Hoots B, et al: Human papillomavirus type distribution in invasive cervical cancer and high-grade cervical lesions: a meta-analysis update. Int J Cancer 121: 621-632, 2007.

3. Kisseljov F, Sakharova O and Kondratjeva T: Cellular and molecular biological aspects of cervical intraepithelial neoplasia. Int Rev Cell Mol Biol 271: 35-95, 2008.

4. Łuczak MW and Jagodziński PP: The role of DNA methylation in cancer development. Folia Histochem Cytobiol 44: 143-154, 2006.

5. Herman JG and Baylin SB: Gene silencing in cancer in association with promoter hypermethylation. N Engl J Med 349: 2042-2054, 2003.

6. Payne SR and Kemp CJ: Tumor suppressor genetics. Carcinogenesis 26: 2031-2045, 2005.

7. Momparler RL: Cancer epigenetics. Oncogene 42: 6479-6483, 2003.

8. Robertson KD: DNA methylation, methyltransferases, and cancer. Oncogene 24: 3139-3155, 2001

9. Bestor TH: The DNA methyltransferases of mammals. Hum Mol Genet 16: 2395-2402, 2000.

10. Cedar H: DNA methylation and gene activity. Cell 53: 3-4, 1988

11. MayerW, Niveleau A, Walter J,Fundele R and Haaf T: Demethylation of the zygotic paternal genome. Nature 403: 501-502, 2000.

12. Jost JP, Oakeley EJ, Zhu B, et al: 5-Methylcytosine DNA glycosylase participates in the genome-wide loss of DNA methylation occurring during mouse myoblast differentiation. Nucleic Acids Res 29: 4452-4461, 2001.

13. Szyf M, Pakneshan P and Rabbani SA: DNA methylation and breast cancer. Biochem Pharmacol 68: 1187-1197, 2004.

14. Kristensen LS, Nielsen HM and Hansen LL: Epigenetics and cancer treatment. Eur J Pharmacol 625: 131-142, 2009.

15. Kanai Y: Alterations of DNA methylation and clinicopathological diversity of human cancers. Pathol Int 58: 544-558, 2008.

16. Kanai Y and Hirohashi S: Alterations of DNA methylation associated with abnormalities of DNA methyltransferases in human cancers during transition from a precancer to a malignant state. Carcinogenesis 28: 2434-2442, 2007.

17. Miremadi A, Oestergaard MZ,Pharoah PD and Caldas C: Cancer genetics of epigenetic genes. Hum Mol Genet 16: R28-R49, 2007.

18. Au Yeung CL, Tsang WP, Tsang TY, Co NN, Yau PL and Kwok TT: HPV-16 E6 upregulation of DNMT1 through repression of tumor suppressor p53. Oncol Rep 24: 1599-1604, 2010.

19. Laurson J, Khan S, Chung R, Cross K and Raj K: Epigenetic repression of E-cadherin by human papillomavirus $16 \mathrm{E} 7$ protein. Carcinogenesis 31: 918-926, 2010.

20. Lin TS, Lee H, Chen RA, et al: An association of DNMT3b protein expression with $\mathrm{P} 16^{\mathrm{INK} 4 \mathrm{a}}$ promoter hypermethylation in non-smoking female lung cancer with human papillomavirus infection. Cancer Lett 226: 77-84, 2005.

21. Unruh A, Ressel A, Mohamed HG, et al: The hypoxia-inducible factor- 1 alpha is a negative factor for tumor therapy. Oncogene 22: 3213-3220, 2003

22. Kaelin WG Jr and Ratcliffe PJ: Oxygen sensing by metazoans: the central role of the HIF hydroxylase pathway. Mol Cell 30: 393-402, 2008

23. Maxwell PH, Wiesener MS, Chang GW, et al: The tumour suppressor protein VHL targets hypoxia-inducible factors for oxygen-dependent proteolysis. Nature 6733: 271-275, 1999.

24. Marín-Hernández A, Gallardo-Pérez JC, Ralph SJ, RodríguezEnríquez S and Moreno-Sánchez R: HIF-1alpha modulates energy metabolism in cancer cells by inducing over-expression of specific glycolytic isoforms. Mini Rev Med Chem 9: 1084-1101, 2009.

25. Weidemann A and Johnson RS: Biology of HIF-1alpha. Cell Death Differ 15: 621-627, 2008.

26. Zhong H, De Marzo AM, Laughner E, et al: Overexpression of hypoxia-inducible factor lalpha in common human cancers and their metastases. Cancer Res 59: 5830-5835, 1999.

27. Puchtler H, Meloan SN and Waldrop FS: Application of current chemical concepts to metal-hematein and -brazilein stains. Histochemistry 85: 353-364, 1986.

28. Chomczynski P and Sacchi N: Single-step method of RNA isolation by acid guanidinium thiocyanate-phenol-chloroform extraction. Anal Biochem 162: 156-159, 1987. 
29. Łuczak MW, Roszak A, Pawlik P, Kedzia H, Lianeri M and Jagodziński PP: Increased expression of HIF-1A and its implication in the hypoxia pathway in primary advanced uterine cervical carcinoma. Oncol Rep 26: 1259-1264, 2011.

30. Lee WY, Huang SC, Hsu KF, Tzeng CC and Shen WL: Roles for hypoxia-regulated genes during cervical carcinogenesis: somatic evolution during the hypoxia-glycolysis-acidosis sequence. Gynecol Oncol 108: 377-384, 2008.

31. Mazibrada J, Rittà M, Mondini M, et al: Interaction between inflammation and angiogenesis during different stages of cervical carcinogenesis. Gynecol Oncol 108: 112-120, 2008.

32. Smith-McCune KK and Weidner N: Demonstration and characterization of the angiogenic properties of cervical dysplasia. Cancer Res 54: 800-804, 1994.

33. Bruick RK and McKnight SL: A conserved family of prolyl4-hydroxylases that modify HIF. Science 5545: 1337-1340, 2001.

34. Hirsilä M, Koivunen P, Günzler V, Kivirikko KI and Myllyharju J: Characterization of the human prolyl 4-hydroxylases that modify the hypoxia-inducible factor. J Biol Chem 278: 30772-30780, 2003 .

35. Tuckerman JR, Zhao Y, Hewitson KS, et al: Determination and comparison of specific activity of the HIF-prolyl hydroxylases. FEBS Lett 576: 145-150, 2004

36. Wenger RH, Stiehl DP and Camenisch G: Integration of oxygen signaling at the consensus HRE. Sci STKE. 306:re12, 2005.

37. Brat DJ, Kaur B and van Meir EG: Genetic modulation of hypoxia induced gene expression and angiogenesis: relevance to brain tumors. Front Biosci 8: D100-D116, 2003.

38. Kimura H, Weisz A, Ogura $\mathrm{T}$, et al: Identification of hypoxiainducible factor 1 ancillary sequence and its function in vascular endothelial growth factor gene induction by hypoxia and nitric oxide. J Biol Chem 276: 2292-2298, 2001.

39. Wenger $\mathrm{RH}$ : Cellular adaptation to hypoxia: $\mathrm{O}_{2}$-sensing protein hydroxylases, hypoxia-inducible transcription factors, and $\mathrm{O}_{2}$-regulated gene expression. FASEB J 16: 1151-1162, 2002.

40. Staller P, Sulitkova J, Lisztwan J, Moch H, Oakeley EJ and Krek W: Chemokine receptor CXCR4 downregulated by von Hippel-Lindau tumour suppressor pVHL. Nature 6955: 307-311, 2003.

41. Chik F and Szyf M: Effects of specific DNMT gene depletion on cancer cell transformation and breast cancer cell invasion; toward selective DNMT inhibitors. Carcinogenesis 32: 224-232, 2011.

42. Ateeq B,Unterberger A,Szyf Mand Rabbani SA:Pharmacological inhibition of DNA methylation induces proinvasive and prometastatic genes in vitro and in vivo. Neoplasia 10: 266-278, 2008.

43. Dejeux E, Rønneberg JA, Solvang H, et al: DNA methylation profiling in doxorubicin treated primary locally advanced breas tumours identifies novel genes associated with survival and treatment response. Mol Cancer 9: 68,2010.

44. Przybylski M, Kozłowska A, Pietkiewicz PP, Lutkowska A, Lianeri $\mathrm{M}$ and Jagodzinski PP: Increased CXCR4 expression in AsPC1 pancreatic carcinoma cells with RNAinterference-mediated knockdown of DNMT1 and DNMT3B. Biomed Pharmacother 64 254-258, 2010

45. Sato N, Matsubayashi H, Fukushima N and Goggins M: The chemokine receptor CXCR4 is regulated by DNA methylation in pancreatic cancer. Cancer Biol Ther 4: 70-76, 2005.

46. Kubarek $€$ and Jagodzinski PP: Epigenetic up-regulation of CXCR4 and CXCL12 expression by 17 beta-estradiol and tamoxifen is associated with formation of DNA methyltransferase 3B4 splice variant in Ishikawa endometrial adenocarcinoma cells. FEBS Lett 581: 1441-1448, 2007.

47. Mori T, Kim J, Yamano T, et al: Epigenetic up-regulation of $\mathrm{C}-\mathrm{C}$ chemokine receptor 7 and $\mathrm{C}-\mathrm{X}-\mathrm{C}$ chemokine receptor 4 expression in melanoma cells. Cancer Res 65: 1800-1807, 2005.

48. Bogani C, Ponziani V, Guglielmelli P, et al: Myeloproliferative Disorders Research Consortium. Hypermethylation of CXCR4 promoter in $\mathrm{CD} 34^{+}$cells from patients with primary myelofibrosis Stem Cells 26: 1920-1930, 2008.
49. Kodama J, Hasengaowa, Kusumoto T, et al: Association of CXCR4 and CCR7 chemokine receptor expression and lymph node metastasis in human cervical cancer. Ann Oncol 18: 70-76, 2007.

50. Zhang JP, Lu WG, Ye F, Chen HZ, Zhou CY and Xie X: Study on CXCR4/SDF-1alpha axis in lymph node metastasis of cervical squamous cell carcinoma. Int J Gynecol Cancer 17: 78-483, 2007.

51. Yang YC, Lee ZY, Wu CC, Chen TC, Chang CL and Chen CP: CXCR4 expression is associated with pelvic lymph node metastasis in cervical adenocarcinoma. Int J Gynecol Cancer 17: 676-686, 2007.

52. Rein DT, Breidenbach M, Nettelbeck DM, et al: Evaluation of tissue-specific promoters in carcinomas of the cervix uteri. J Gene Med 11: 1281-1289, 2004

53. Tang B, Qu Y, Zhao F, et al: In vitro effects of hypoxia-inducible factor 1alpha on the biological characteristics of the SiHa uterine cervix cancer cell line. Int J Gynecol Cancer 19: 898-904, 2009.

54. La Salle S and Trasler JM: Dynamic expression of DNMT3a and DNMT3b isoforms during male germ cell development in the mouse. Dev Biol 296: 71-82, 2006.

55. Chen T, Ueda Y, Xie S and Li E: A novel Dnmt3a isoform produced from an alternative promoter localizes to euchromatin and its expression correlates with active de novo methylation. J Biol Chem 277: 38746-38754, 2002.

56. Weisenberger DJ, Velicescu M, Preciado-Lopez MA, et al: Identification and characterization of alternatively spliced variants of DNA methyltransferase 3a in mammalian cells. Gene 298: 91-99, 2002

57. Okano M, Bell DW, Haber DA and Li E: DNA methyltransferases Dnmt3a and Dnmt3b are essential for de novo methylation and mammalian development. Cell 99: 247-257, 1999.

58. Deng T, Kuang Y, Wang L, Li J, Wang Z and Fei J: An essential role for DNA methyltransferase $3 \mathrm{a}$ in melanoma tumorigenesis. Biochem Biophys Res Commun 387: 611-616, 2009.

59. Ng EK, Tsang WP, Ng SS, et al: MicroRNA-143 targets DNA methyltransferases $3 \mathrm{~A}$ in colorectal cancer. Br J Cancer 101: 699-706, 2009.

60. Daniel FI, Rivero ER, Modolo F, Lopes TG and Salum FG: Immunohistochemical expression of DNA methyltransferases 1 , $3 \mathrm{a}$ and $3 \mathrm{~b}$ in oral leukoplakias and squamous cell carcinomas. Arch Oral Biol 55: 1024-1030, 2010.

61. Qu Y, Mu G, Wu Y, et al: Overexpression of DNA methyltransferases $1,3 \mathrm{a}$, and $3 \mathrm{~b}$ significantly correlates with retinoblastoma tumorigenesis. Am J Clin Pathol 134: 826-834, 2010.

62. Zhao Z, Wu Q, Cheng J, Qiu X, Zhang J and Fan H: Depletion of DNMT3A suppressed cell proliferation and restored PTEN in hepatocellular carcinoma cell. J Biomed Biotechnol ID:737535, 2010.

63. Choi SH, Heo K, Byun HM, An W, Lu W and Yang AS: Identification of preferential target sites for human DNA methyltransferases. Nucleic Acids Res 39: 104-118, 2011.

64. Robert MF, Morin S, Beaulieu N, et al: DNMT1 is required to maintain CpG methylation and aberrant gene silencing in human cancer cells. Nat Genet 33: 61-65, 2003

65. Beaulieu N, Morin S, Chute IC, Robert MF, Nguyen H and MacLeod AR: An essential role for DNA methyltransferase DNMT3B in cancer cell survival. J Biol Chem 277: 28176-28181, 2002.

66. Sawada M, Kanai Y, Arai E, Ushijima S, Ojima H and Hirohashi S: Increased expression of DNA methyltransferase 1 (DNMT1) protein in uterine cervix squamous cell carcinoma and its precursor lesion. Cancer Lett 251: 211-219, 2007.

67. Burgers WA, Blanchon L, Pradhan S, De Launoit Y, Kouzarides T and Fuks F: Viral oncoproteins target the DNA methyltransferases. Oncogene 26: 1650-1655, 2007. 